\title{
Combination Gel Formulation Extracts of Moringa Leaf and Red Betel Leaf as an Inhibitor of Acne-Causing Bacteria (Propionibacterium acne and Staphylococcus aureus)
}

\author{
Eko Sri Wahyuningsih*, Wahono Sumaryono, Chaidir
}

Faculty of Pharmacy, Universitas Pancasila, Indonesia

\begin{tabular}{l}
\hline \hline \multicolumn{1}{c}{ Article info } \\
\hline History \\
Submission: $17-07-2020$ \\
Review: $26-11-2020$ \\
Accepted: $24-02-2021$ \\
"Email: \\
ekosriwahyuningsih@yahoo.co.id
\end{tabular}

DOI: $10.33096 /$ jffi.v8i3.727

Keywords:

Moringa leaves; Piper

crocatum leaves; P. acne;

$S$. aureus; gel form

\begin{abstract}
The most common skin disorder is acne (Acne vulgaris) which is a chronic inflammatory disease that occurs in the pilosebaceous unit. Infection can be caused by Propionibacterium acnes and Staphylococcus aureus. Moringa leaves are known to inhibit acne growth. Piper crocatum leaves are also thought to have antibacterial activity. The study aims to determine the effect of the combination of the two extracts in inhibiting the growth of acne-causing bacteria, also tested the gel formula to meet physical and chemical parameters as well as stability to temperature and storage, also to test the acute dermal irritation against rabbit. Each extract with a concentration of $0.3 \% ; 0.6 \% ; 1.25 \% ; 2.5 \% ; 5 \% ; 10 \% ; 20 \%$, incubated then measured the inhibition zone, then determined the minimum inhibition zone concentration of the two extracts to determine the lowest levels of the extracts which still gave antibacterial activity against the tested bacteria by the well diffusion method. The extract combination was formulated in a gel preparation with the excipients Carbopol 940, PG, Phenoxyethanol, TEA, CMC, and Aquadest. Antibacterial activity test for gel preparations used the well method with positive control Medi-Klin ${ }^{\circledR}$ gel. Then the formula evaluation includes physical, chemical, and microbiological evaluations. The results showed that the combination gel form had activity against $P$. acne and S. aureus at concentrations of $2.5 \%: 2.5 \%$. The combination gel preparation of the two extracts also has synergistic effect in inhibiting acne bacteria. The formula can meet physical and chemical parameters and is stable to temperature and storage.
\end{abstract}

\section{Introduction}

The most common skin disorder is acne (Acne vulgaris), this disease occurs especially in adulthood, young and can heal itself (Igarashi, Nishino and Nayar, 2005). Acne (acne) is an abnormal condition of the skin due to disruption of the production of oil glands (sebaceous gland), which causes excess oil production. This condition triggers blockage of hair follicle ducts and skin pores (Mumpuni and Wulandari, 2010). Some argue that acne or acne is an inflammatory disease that affects the pilosebaceous structure, namely the palate glands with hair follicles (Kusantati, Prihatin and Wiana, 2008).

Causes of acne include genetic, endocrine, psychological, season, stress, food, sebaceous gland activity, bacterial infection, cosmetics, and other chemicals (Al-Hoqail, 2003). Infection can be caused by Propionibacterium Acnes which plays a role in irritation of the follicular epithelium and facilitates the occurrence of Acne vulgaris. Staphylococcus epidermidis and Staphylococcus aureus can cause secondary infections in acne, the infection will get worse if the acne has festered (Mitsui, 1997).

The way to prevent or treat acne is by using systemic or topical antibiotics. For topical treatments, comedolytic and anti-inflammatory comedolytic and anti-inflammatory topical retinoids are used. Tretinoin and tazarotene are usually used. Topical retinoids have the effect of thinning the stratum corneum. Topical antibiotics are usually erythromycin, clindamycin in a single dose is usually combined with benzoyl peroxide to reduce the risk of resistance. For systemic treadments, tetracycline, minocycline, doxycycline, trimethoprim alone, or in combination with sulfamethoxazole and azithromycin are usually used (Mitsui, 1997). These drugs have side effects such as resistance to antibiotics and can thin the stratum corneum.

A natural ingredient that has antibacterial activity and has the potential to be developed in a preparation that can inhibit acne growth is Moringa leaves. Moringa leaves have broad therapeutic effects such as antipyretic, anti-plasma, anti- 
inflammatory, anti-arthritis, and antibacterial (Isitua, Ibeh and Olayinka, 2016).

Red betel leaves contain alkaloids, flavonoids, tannins, saponins, essential oils which are thought to have antibacterial power. Based on the results of previous research, a combination of Moringa leaf extract and red betel leaf extract will be examined against the bacteria Staphylococcus aureus and Propionibacterium acnes that cause acne and are expected to have a better effect (Rachmawaty, 2017).

There are various forms of acne medication on the market, some in the form of creams, masks, tablets, and many more. Gel preparations were chosen because they have several advantages, namely easy to use, easy to clean, do not contain oil and give a cold feeling, have properties and better stability in application when compared to cream or ointment preparations (Kaur and Guleri, 2013). A good pharmaceutical preparation, besides having to meet safety parameters, also has an optimum composition.

Gel is a semisolid system consisting of a suspension made of small inorganic particles or large organic molecules, penetrated by a liquid. The gel is sometimes called jelly (Harborne, 1996). Gel is a soft mass preparation, in the form of a suspension made from small particles of organic compounds or macromolecular organic compounds, each of which is encased and mutually absorbed by liquid (Shanson, 1982).

Based on the description above, a research will be carried out by making a gel preparation formula containing the active ingredient combination of $96 \%$ ethanol extract of Moringa leaves and red betel leaves with varying concentrations of the extract and test for antibacterial activity that causes acne. The gel base used was carbopol 940 and compared to other gels on the market as a positive control. The effectiveness test of anti-acne gel preparations was carried out by using the diffusion method against Staphylococcus aureus and Propionibacterium acnes bacteria.

\section{Research Method \\ II.1 Materials}

Moringa leaf extract and red betel leaf, $96 \%$ ethanol, aluminum foil, Whatman filter paper no. 1, phytochemical screening reagent, Mc Standard solution. Farland no. 0.5, propylene glycol, carbopol 940, distilled water, pure culture of Staphylococcus aureus bacteria which is a collection from the Laboratory Unit, DMSO, Propionibacterium acnes bacteria culture, Nutrient Agar (NA), and blood agar.

\section{II.2 Extraction}

The extraction process used is maceration where the simplicia is extracted using $70 \%$ ethanol with ratio of $1: 10$, then filtered using Whatman filter paper no. 1. The extraction process is continued until the filtrate is clear, colorless. The collected filtrate is evaporated and concentrated using a vacuum rotary evaporator to form a thick extract. The viscous extract obtained is packed in a tightly closed container and stored in the refrigerator.

\section{II.3 Test the extract's antibacterial activity II.3.1 Sterilization Tools}

The tools used to test the effectiveness of bacteria such as glasses, Petri dishes, and test tubes are washed with running water then drained and oven at $150^{\circ} \mathrm{C}$ for 2 hours.

\section{II.3.2 Bacterial Regeneration}

Bacterial rejuvenation is done by, bacterial colonies are taken from the pure strain colony using a sterile loop needle then scratched on TSA media for $S$. aureus bacteria then incubated at $37^{\circ} \mathrm{C}$ for 24 hours and BHIA for $P$. acne bacteria then incubated at $37^{\circ} \mathrm{C}$ for 48 hours.

\section{II.3.3 Preparation of Bacterial Suspension}

Sterile $0.9 \% \mathrm{NaCl}$ was inserted into a test tube, then took the bacteria culture using a loop needle then put it in $0.9 \% \mathrm{NaCl}$ solution and then shaken it until the turbidity was obtained which was adjusted to the Mc Farland turbidity standard 0.5 $(108 \mathrm{CFU} / \mathrm{ml})$. If it is less cramped, colony is added and if it is too cloudy, $0.9 \% \mathrm{NaCl}$ is added.

\section{II.3.4 Bacterial Activity Test}

Moringa leaf extract and red betel leaf were each weighted according to the concentration to be tested, namely $0.3 \% ; 0.6 \% ; 1.25 \% ; 2.5 \% ; 5 \% ; 10 \%$; $20 \%$ then dissolved in sterile aquadest to $1 \mathrm{~mL}$. The extract was then put into an agar well as much as $50 \mu \mathrm{L}$ (each concentration variation) and given positive control and negative control and then incubated for $1 \times 24$ hours at $37^{\circ} \mathrm{C}$ (for $S$. aureus) and for $P$. acne incubated for $2 \times 24$ hours at $37^{\circ} \mathrm{C}$ put in the anaerob jar. After incubation, the diameter of the inhibition zone was measured by looking at the clear zone area using a caliper. Positive control used clindamycin and negative control used sterile aquabidest.

\section{II.3.5 Single Extract MIC Determination Test}

The minimum inhibitory concentration of Moringa leaf extract and red betel leaf was determined to determine the lowest level of the extract which still provides antibacterial activity against the tested bacteria by the well diffusion method.

\section{II.4 Making Gel Formula}

The thick extract of Moringa leaves and red betel leaf was dissolved in the aquadest until mixed. Carbopol 940 is grown for 24 hours in distilled water which has been filled with a combination of extracts covered with aluminum foil. CMC was developed with aquadest, then mixed to No. 2. Phenoxyethanol is added to propylene glycol and then added to the base mixture of CMC and carbopol 940, stirred until 
homogeneous using a homogenizer. Neutralization was carried out using triethanolamine (TEA) until a thick and clear gene base was obtained with a $\mathrm{pH}$ of 4.5 - 6.5 then stirred again until it was homogeneous. Enough gel volume using distilled water up to 100 grams then stir again until homogeneous. The preparation that has been made is then put into a tightly closed container for evaluation of the gel.

\section{II.5 Gel Formula Inhibition Diameter Test}

Antibacterial activity test of gel preparations was carried out using the well method. Each medium that was still in the form of liquid was inserted into a bacterial inoculum as much as $1 \mathrm{ml}$ (BHIA media for $P$. acne and TSB media for $S$. aureus). After that, it is poured into a sterile $20 \mathrm{ml}$ petri dish and allowed to solidify. After the agar is solidified, a hole is made in the media by inserting a sterile mount. After that, each hole was added to the respective formula as much as 0.5 grams. The positive control used mediclin ${ }^{\circledR}$ gel while the negative control used F1 (base). Each petri dish was then incubated at $37^{\circ} \mathrm{C}$ for $2 \times 24$ hours under anaerobic conditions for $P$. acne in an anaerobic jar, while for $S$. aureus bacterial incubated for $1 \times 24$ hours at $37^{\circ} \mathrm{C}$.

\section{II.6 Evaluation of Gel Preparations}

Formula evaluation includes physical, chemical, and microbiological evaluations. Physical evaluation includes organoleptic examination, spreadability, homogeneity, viscosity, and irritation test on preparations. Chemical evaluation includes determining $\mathrm{pH}$. Microbiological evaluation included determining the antibacterial effectiveness of the combination gel preparation of red betel leaf and Moringa leaf extract against $P$. acnes and $S$. aureus bacteria.

\section{II.7 Acute Dermal Irritation Test}

Dermal acute irritation test was carried out on three rabbits, before starting the test, the test animals were acclimatized in the experimental room for about 5 days and the animals were placed in individual cages. At least 24 hours before the test, the hair of the animal is shaved over the dorsal area of $10 \times 15 \mathrm{~cm}$ for exposure of the test preparation. Shaving starts from the scapula area to the basebone and halfway down the body on each side. The test area on the rabbit's back is divided into 4 sections each measuring $\pm 2 \times 3 \mathrm{~cm}$. The location is divided into 2 locations for blanks and 2 locations for application of gel preparations. All test animals observed the presence or absence of erythema and edema, response assessments were carried out at 1 , 24,48 , and 72 hours after opening the patch. The test site is examined and observed for changes as a skin reaction to the test material and assessed by giving 0 to 4 the severity of the observed skin reactions.

\section{II.8 Data analysis}

The data obtained will then be analyzed the data. Stability test data using two-way ANOVA.

\section{Results and Discussion \\ III.1 Simplicia quality standardization}

The results of the simplicia quality standardization obtained the soluble compound content of moringa leaves 14.63 ethanol, 10.85 red betel leaves. Water content of moringa leaves 8.44, red betel leaf 9.25. The ash content of Moringa leaves was $8.73,12.81$ red betel leaves. Acid insoluble ash content of Moringa leaves is 0.22 , red betel leaves 0.66 .

\section{III.2 Phytochemical screening}

The results of phytochemical screening of Moringa leaf extract and red betel leaf extract contain alkaloids, flavonoids, saponins, tannins, terpenoids, and steroids.

\section{III.3 The results of the antibacterial activity of moringa leaf extract and red betel leaf \\ Testing for antibacterial activity was carried out using the agar well diffusion method, where each well was given $40 \mu \mathrm{L}$ of the test extract. The positive control used clindamycin powder and the negative control used was $10 \%$ DMSO solution. The results of measurements of the average diameter of the inhibition zone of Moringa leaf extract and red betel leaf can be seen in Tables 1 and 2 .}

Table 1. Antibacterial activity of Moringa leaf extract

\begin{tabular}{cll}
\hline $\begin{array}{c}\text { Concentration } \\
(\%)\end{array}$ & \multicolumn{2}{l}{ Average Moringa Leaf Extracts $(\mathbf{m m}) \pm$ SD } \\
\cline { 2 - 3 } P. acne & S. aureus \\
\hline 20 & $26,45 \pm 0,07$ & $23,20 \pm 0,14$ \\
10 & $17,25 \pm 0,21$ & $20,50 \pm 0,28$ \\
5 & $15,58 \pm 0,10$ & $19,60 \pm 0,28$ \\
2,5 & $12,28 \pm 0,25$ & $15,45 \pm 0,35$ \\
1,25 & $10,80 \pm 0,14$ & $11,45 \pm 0,35$ \\
0,6 & $0 \pm 0$ & $0 \pm 0$ \\
0,3 & $0 \pm 0$ & $0 \pm 0$ \\
0,1 & $0 \pm 0$ & $0 \pm 0$ \\
$\mathrm{~K}^{+}$ & $29,45 \pm 0,35$ & $29,40 \pm 0,14$ \\
$\mathrm{~K}^{-}$ & $0 \pm 0$ & $0 \pm 0$ \\
\hline
\end{tabular}


Information: Positive control $(+)=$ Clindamycin; Negative control $(-)=$ DMSO 10\%; $\mathrm{SD}=$ Standard Deviation

Table 2. Antibacterial activity of red betel leaf extract

\begin{tabular}{cll}
\hline $\begin{array}{c}\text { Concentration } \\
(\boldsymbol{\%})\end{array}$ & \multicolumn{2}{c}{ Average Red Betel Leaf Extracts $(\mathbf{m m}) \pm$ SD } \\
\cline { 2 - 3 } P. acne & S. aureus \\
\hline 20 & $17,45 \pm 0,28$ & $18,35 \pm 0,42$ \\
10 & $15,50 \pm 0,07$ & $17,20 \pm 0,14$ \\
5 & $13,75 \pm 0,28$ & $12,50 \pm 0,57$ \\
2,5 & $12,65 \pm 0,14$ & $11,4 \pm 0,42$ \\
1,25 & $0 \pm 0$ & $0 \pm 0$ \\
0,6 & $0 \pm 0$ & $0 \pm 0$ \\
0,3 & $0 \pm 0$ & $0 \pm 0$ \\
0,1 & $0 \pm 0$ & $0 \pm 0$ \\
$\mathrm{~K}^{+}$ & $29,40 \pm 0,35$ & $30,4 \pm 0,14$ \\
$\mathrm{~K}^{-}$ & $0 \pm 0$ & $0 \pm 0$ \\
\hline
\end{tabular}

Information: Positive control (+) = Clindamycin; Negative control (-) = DMSO 10\%;

$\mathrm{SD}=$ Standard Deviation

\section{III.4 Gel Formulation Results}

The choice of carbopol 940 as a gelling agent is because carbopol has good stability and does not experience changes in viscosity for a long time or is caused by temperature and is not easily contaminated by bacteria. The use of $2 \%$ carbopol is based on the results of the optimization to determine the best formula. Carbopol $2 \%$ is the best result obtained, but when the formula is added with the combination of extracts, the formula becomes thinner (viscosity drops significantly and $\mathrm{pH}$ drops). The addition of $2 \%$ CMC can increase the viscosity of the gel preparation. Propylene glycol functions as a humectant to maintain gel stability by absorbing moisture from the environment and reducing water evaporation from the preparation so that it can retain skin moisture and skin does not dry out. Phenoxyethanol acts as a preservative, a preservative is needed in gel formulas given that the high water content in the gel preparation can cause microbial contamination. Triethanolamine is used to neutralize $\mathrm{pH}$ (alkalizing agent), because the extracts of Moringa leaves and red betel leaf are acidic so triethanolamine is needed to stabilize $\mathrm{pH}$, besides that TEA also functions to develop carbopol 940 and the gel to be stable.

Table 3. The results of the diameter inhibition test in the formula

\begin{tabular}{cll}
\hline $\begin{array}{c}\text { Concentration } \\
\text { (\%) }\end{array}$ & DDH & S. aureus \\
\cline { 2 - 3 } F1 & $12,80 \pm 0,14$ & $12,20 \pm 0,14$ \\
F2 & $12,15 \pm 0,11$ & $11,40 \pm 0,42$ \\
F3 & $18,40 \pm 0,42$ & $15,60 \pm 0,42$ \\
F4 & $0 \pm 0$ & $14,75 \pm 0,07$ \\
$\mathrm{~K}^{+}$ & $29,15 \pm 0,07$ & $29,40 \pm 0,14$ \\
$\mathrm{~K}^{-}$ & $0 \pm 0$ & $0 \pm 0$ \\
\hline Information: Positive control (+) = Clindamycin; Negative control $(-)=$ DMSO 10\%;
\end{tabular}

Based on the Table 3, it can be seen that F1 preparation has the same inhibitory power against $P$. acne and $S$. aureus bacteria, while F2 has a greater inhibitory power against $P$. acne bacteria than against $S$ aureus bacteria. F3 which is a combination of Moringa leaf extract and red betel leaf with a concentration (2.5: 2.5) shows an increase in the diameter of inhibition of $18 \mathrm{~mm}$ for P. acne bacteria and $15 \mathrm{~mm}$ for $\mathrm{S}$ aureus bacteria, this shows that the combination of leaf extract Moringa and red betel leaf provide a synergistic work performance by showing a larger diameter of inhibition than the single extract. In F4, namely the combination of Moringa leaf extract and red betel leaf $(5: 2,5)$, there is no inhibition zone against $P$. acne bacteria and there is an inhibition zone against $S$. aureus bacteria by $14 \mathrm{~mm}$ (smaller inhibition zone than in F4). So it can be concluded that increasing the concentration of the combination does not guarantee an increase in inhibition but even decreases activity. An increase in the diameter value of the inhibitory power of the preparation could be caused by an increase in the penetration of compounds in the extract that diffuse into the media. The result of the 2-way ANOVA test shows a sig value of $0.000<0.05$, which means that there is a difference between each formula (single and combined).

\section{III.5 Evaluation Results of Gel}

Preparations Organoleptic test is carried out to determine the physical changes in the preparation formula including color, odor, and shape 
as stability parameters of a preparation. The test results show that $\mathrm{F} 1$ and $\mathrm{F} 2$ are brown, have a distinctive mild odor (distinct characteristic) and semisolid textures. Formula 3 is dark brown in color, has a distinctive light odor and semisolid texture, while F4 shows a dark brown color, slightly sharp odor, and semisolid texture. The smell of each formula has a characteristic odor caused by the active substance. The addition of the active substance to the base reduces the viscosity of the preparation to become more dilute.

Homogeneity test conducted to see the homogeneity (uniformity) of the formulation in each formula, including whether or not the base is not mixed, and the presence or absence of coarse grains or lumps in the preparation. The test results show that both F1, F2, F3, and F4 are homogeneous formulas with flat surfaces and no coarse grains/lumps indicating that all formulas are evenly mixed (homogeneous).

Spreadability test conducted to determine the spreadability of a formula in the presence of pressure. A dispersible preparation will ensure ease of use on the skin. Good spreadability has a range between $5-7 \mathrm{~cm}$. The spreadability test results for F1, F2, F3, and F4 have $5.7-6.8$, this indicates that all gel formulas have good dispersive power.

$\mathrm{pH}$ test conducted to determine the degree of acidity of the preparation formula. The preparation formula must meet the physiological $\mathrm{pH}$ parameters of human skin because a $\mathrm{pH}$ of a preparation that is too acidic will cause irritate, while a $\mathrm{pH}$ that is too alkaline will cause scaly skin. Based on the results of the study, it can be seen that $\mathrm{F} 1, \mathrm{~F} 2, \mathrm{~F} 3$, and $\mathrm{F} 4$ have a $\mathrm{pH}$ range that is still in accordance with the skin's pH, namely 4.5-6.5. So it can be assumed that all the preparation formulas are safe for application on the skin.

Viscosity test conducted to determine the viscosity value in each formula. The spindle used is spindle number 5 , with a rotation speed of $50 \mathrm{rpm}$ for 60 seconds. The test results showed that F1, which is the gel base, has the highest viscosity among F2, F3, and F4. While the lowest viscosity is F4 which contains the largest concentration of active substances, namely the combination of Moringa leaf extract and red betel leaf (5: 2.5) compared to formulas F1, F2, F4. Viscosity is inversely proportional to the dispersion power where high viscosity causes the spreadability of the preparation is low or the higher the viscosity, the greater the resistance.

\section{III.6 Gel Preparation Stability Test}

Results carried out to determine the physical and chemical stability of each formula including the organoleptic test, viscosity, $\mathrm{pH}$, spreadability, and homogeneity. Formula 3 was chosen as the best formula with the best characteristic test parameters and the best DDH. The stability test carried out in this study was the stability test at high temperatures, namely at $40^{\circ} \mathrm{C}$, room temperature $25-30^{\circ} \mathrm{C}$, and low temperature $4{ }^{\circ} \mathrm{C}$ for 12 weeks. Observations were made every 2 weeks starting from weeks 2, 4, 6, 8, 10, 12. Gel was declared stable if there were no significant differences in the results of the parameters observed every 2 weeks seen from the sig value> 0.05 .

Organoleptic test results showed that there was no physical change in the acne gel preparation including color, odor, and texture both at storage at $4^{\circ} \mathrm{C}$, storage at room temperature. This shows that the acne gel preparation is physically stable during the shelf life of 12 weeks.

Homogeneity test three gel preparations with storage at three different temperatures showed that the gel was homogeneous as evidenced by the absence of coarse granules.

Spreadability test results of good gel preparation are 5-7 cm or $5.54-6.08 \mathrm{~cm}$ (based on SNI standards). The greater the dispersibility of the preparation, the greater the ability of the active substance to spread and the wider skin contact. The viscosity value is inversely proportional to the spreadability, meaning that the higher the viscosity, the smaller the spreadability. The results of the evaluation of the spreadability obtained at $4^{\circ} \mathrm{C}$, room temperature, and $40^{\circ} \mathrm{C}$ ranged from 5.7 to $6.3 \mathrm{~cm}$. This indicates that the dispersibility of all formulas obtained meets the requirements so that the gel will spread well when applied.

$\mathrm{pH}$ test value during storage at $4^{\circ} \mathrm{C}$, room temperature, and $40^{\circ} \mathrm{C}$, the resulting $\mathrm{pH}$ of the gel for 12 weeks at all temperatures ranged from 5.31 5.63 .

\section{III.7 Microbial Contamination Test}

Testing for microbial contamination was carried out at week 0 and week 12 on preparations stored at $4^{\circ} \mathrm{C}, 27^{\circ} \mathrm{C}$, and $40^{\circ} \mathrm{C}$. The results of the microbial contamination test using the ALT method on the gel preparation showed negative results up to 10-3 dilutions with negative control based on gel without extract. According to PerKa BPOM, Number 17 of 2014, the requirements for microbial contamination for cosmetics other than for children under 3 years, the area around the eyes and mucous membranes contain no more than 103 colonies/gram.

\section{III.8 Antibacterial Activity Test Results for Gel Preparations}

The gel activity test of the combination of extracts showed that the formula made had antibacterial activity which was characterized by the emergence of an inhibition zone against $S$. aureus and $P$. acnes bacteria. In the table above, the inhibition zone of the formula against $P$. acnes bacteria after storage after $4^{\circ} \mathrm{C}$ storage has an inhibition zone that is almost the same as before storage (week 0), but at storage temperature $27^{\circ} \mathrm{C}$ has a decreased inhibition zone, while at $40^{\circ} \mathrm{C}$ it has 
a zone resistance is almost the same as before storage. The inhibition zone in $S$. aureus bacteria after 12 weeks of storage decreased the inhibition zone in storage at $4^{\circ} \mathrm{C}, 27^{\circ} \mathrm{C}$, and a temperature of $40^{\circ} \mathrm{C}$. The decrease in the diameter of the inhibition zone in the combination extract gel formula could be caused by temperature and storage time although the decrease was very small.

\section{III.9 Statistical Test Analysis}

T-test statistical analysis was carried out to see the difference in the area of bacterial inhibition zone produced by the combination gel extract against various storage temperatures after storage for 12 weeks. Interpretation of the analysis results is a significant value $<0.05$, so there is a significant difference in the area of the inhibition zone produced by the combination gel extract against the storage temperature. A significant value $>0.05$ indicates that there is no significant difference in the area of the inhibition zone produced by the combination gel extract against storage temperature. The results of the analysis obtained were significant values $>0.05$, which indicated that there was no significant difference in the inhibition diameter (DDH) of the combination gel against various storage temperature conditions.

\section{III.10 Animal Irritation Test}

The results in table 4 show a slight erythema reaction but it is not clear but it does not cause edema after 3 days of treatment. With clear boundaries but did not cause edema at 48 and 72 hours of treatment. This result is not classified as dangerous because basically, the sensitivity of animal skin is slightly different from human skin. On the third day, the rabbits did not experience erythema and edema. On the second day, the three rabbits had erythema and no one had edema. On the third day, all three rabbits had clearly defined erythema but did not cause edema in groves at 48 hours and 72 hours. This result is not classified as dangerous because basically, the sensitivity of animal skin is slightly different from human skin.

Table 4. Animal Irritation Test Results on Rabbits

\begin{tabular}{|c|c|c|c|c|c|c|c|c|c|c|c|c|c|c|c|c|c|c|}
\hline \multirow{3}{*}{ Time } & \multicolumn{6}{|c|}{ Rabbits 1} & \multicolumn{6}{|c|}{ Rabbits 2} & \multicolumn{6}{|c|}{ Rabbits 3} \\
\hline & \multicolumn{2}{|c|}{$5^{\circ} \mathrm{C}$} & \multicolumn{2}{|c|}{$27^{\circ} \mathrm{C}$} & \multicolumn{2}{|c|}{$40^{\circ} \mathrm{C}$} & \multicolumn{2}{|c|}{$5^{\circ} \mathrm{C}$} & \multicolumn{2}{|c|}{$27^{\circ} \mathrm{C}$} & \multicolumn{2}{|c|}{$40^{\circ} \mathrm{C}$} & \multicolumn{2}{|c|}{$5^{\circ} \mathrm{C}$} & \multicolumn{2}{|c|}{$27^{\circ} \mathrm{C}$} & \multicolumn{2}{|c|}{$40^{\circ} \mathrm{C}$} \\
\hline & $\mathbf{E}$ & $\mathbf{U}$ & $\mathbf{E}$ & $\mathbf{U}$ & $\mathbf{E}$ & $\mathbf{U}$ & $\mathbf{E}$ & $\mathbf{U}$ & $\mathbf{E}$ & $\mathbf{U}$ & $\mathbf{E}$ & $\mathbf{U}$ & $\mathbf{E}$ & $\mathbf{U}$ & $\mathbf{E}$ & $\mathbf{U}$ & $\mathbf{E}$ & $\mathbf{U}$ \\
\hline 24 hours & 0 & 0 & 0 & 0 & 0 & 0 & 0 & 0 & 0 & 0 & 0 & 0 & 0 & 0 & 0 & 0 & 0 & 0 \\
\hline 48 hours & 1 & 0 & 0 & 0 & 1 & 0 & 1 & 0 & 0 & 0 & 0 & 0 & 0 & 0 & 1 & 0 & 0 & 0 \\
\hline 72 hours & 2 & 0 & 1 & 0 & 2 & 0 & 1 & 0 & 1 & 0 & 0 & 0 & 1 & 1 & 2 & 0 & 1 & 0 \\
\hline total & 3 & 0 & 1 & 0 & 3 & 0 & 2 & 0 & 1 & 0 & 0 & 0 & 1 & 1 & 3 & 0 & 1 & 0 \\
\hline
\end{tabular}

Information: $\mathrm{E}=$ Erythema; $\mathrm{U}=$ Udema Primary irritation index: 0.33; Conclusion: The response category is very light

\section{Conclusions}

The combination gel preparation of Moringa leaf extract and red betel leaf has a synergistic effect in inhibiting acne bacteria, the best inhibition against Propionibacterium acnes and Staphylococcus aureus bacteria as acne-causing bacteria at a concentration of $2.5 \%: 2.5 \%$. Meet physical and chemical parameters stable to temperature and storage time with optimum combination concentration in the gel formula gives a primary irritation index of 0.33 , including the very mild response category.

\section{References}

Al-Hoqail, I. A. (2003) 'Knowledge, Beliefs and Perception of Youth Toward Acne Vulgaris', audi medical journal, 24(7), pp. 765-8.

Harborne, J. B. (1996) Metode Fitokimia: Penuntun Cara Modern Menganalisis Tumbuhan. Edited by K. Padmawinata and I. Soediro. Bandung: Penerbit ITB.

Igarashi, T., Nishino, K. and Nayar, S. K. (2005) The Appearance of Human Skin. New York. Available at: https://academiccommons.columbia.edu/d oi/10.7916/D8QR589C.

Isitua, C. C., Ibeh, I. N. and Olayinka, J. N. (2016)
'Antibacterial Activity of Moringa oleifera Lam Leaves on Enteric Human Pathogens', Indian Journal of Applied Research, 6(8), pp. 553-557.

Kaur, L. and Guleri, T. K. (2013) 'Topical Gel: A Recent Approach for Novel Drug Delivery', Asian Journal of Biomedical and Pharmaceutical Sciences, 3(17), pp. 1-5. doi: 10.15272/AJBPS.V3I17.183.

Kusantati, H., Prihatin, P. T. and Wiana, W. (2008) Tata Kecantikan Kulit untuk SMK. Jilid 1. Jakarta: Direktorat Jenderal Manajemen Pendidikan Dasar dan Menengah, Departemen Pendidikan Nasional.

Mitsui, T. (1997) New Cosmetic Science. 1st Editio. Amsterdam: Elsevier Science.

Mumpuni, Y. and Wulandari, A. (2010) Cara Jitu Mengatasi Jerawat. Yogyakarta: Penerbit Andi.

Rachmawaty, F. J. (2017) Sirih Merah dalam Kajian Ilmiah. Yogyakarta: Aswaja Pressindo.

Shanson, D. C. (1982) Microbiology in Clinical Practice. Bristol: Wright PSG. 